\title{
Blocking of autocrine IGF-1 reduces viability of human umbilical cord mesenchymal stem cells via inhibition of the Akt/Gsk-3ß signaling pathway
}

\author{
QI WANG ${ }^{1}$, FENXI ZHANG ${ }^{1,2}$ and YAN HONG ${ }^{1}$ \\ ${ }^{1}$ Department of Histology and Embryology, Guizhou Medical University, Guiyang, Guizhou 550004; \\ ${ }^{2}$ Stem Cell Center, Xinxiang Medical University, Xinxiang, Henan 453003, P.R. China
}

Received March 24, 2016; Accepted May 9, 2017

DOI: $10.3892 / \mathrm{mmr} .2018 .8445$

\begin{abstract}
Human umbilical cord mesenchymal stem cells (hUCMSCs) are able to secrete growth factors, such as hepatocyte growth factor, vascular endothelial growth factor and insulin-like growth factor-1 (IGF-1). The secretion of these growth factors by transplanted hUCMSCs have been identified to stimulate the growth of the host cells in the target organs or tissues. The aim of the present study was to investigate the effect of autocrine IGF-1 on cell viability of hUCMSCs. The expression levels of IGF-1 and the IGF-1 receptor (IGF-1R) in hUCMSCs were identified using immunocytochemistry staining. In order to block autocrine IGF-1, hUCMSCs were treated with $5 \mu \mathrm{g} / \mathrm{ml}$ $\alpha$ IR-3, a specific IGF-1R antibody, for $24 \mathrm{~h}$. The cells cultured in medium without $\alpha$ IR-3 were used as the control group. Cell viability, apoptosis, cell cycle and the proliferation-associated proteins were quantified using an MTT assay, flow cytometry and western blotting. The findings of the present study revealed that IGF-1 and IGF-1R were positively expressed in hUCMSCs. Treatment with $\alpha$ IR-3 significantly reduced cell viability and increased apoptosis of hUCMSCs $(\mathrm{P}<0.01)$. Cell cycle analysis indicated that the number of cells in the $\mathrm{G} 2 / \mathrm{M}$ phase was reduced in the $\alpha$ IR-3-treated group compared with the control group. Western blotting revealed that the expression levels of phosphorylated (p)-protein kinase B (Akt), p-glycogen synthase kinase $3 \beta$ (GSK-3 $\beta$ ), p-p70 S6 kinase and cyclin D1 were markedly reduced and p21 expression was markedly increased in the $\alpha$ IR-3-treated group as compared with the control group $(\mathrm{P}<0.05)$. However, no significant difference was identified in the p-extracellular-signal regulated kinase $1 / 2$ expression when the $\alpha$ IR-3 treatment group was compared with the control
\end{abstract}

Correspondence to: Professor Yan Hong, Department of Histology and Embryology, Guizhou Medical University, Dongqing Road, Guiyang, Guizhou 550004, P.R. China

E-mail: hongyanb@163.com

Key words: human umbilical cord mesenchymal stem cells, cell viability, cell apoptosis, insulin-like growth factor-1, autocrine, Akt signaling group. ( $\mathrm{P}>0.05)$. The findings of the present study suggested that the autocrine IGF-1 from hUCMSCs may be capable of influencing cell viability of hUCMSCs, which may be associated with activation of Akt/GSK-3 $\beta$ signaling pathway.

\section{Introduction}

Mesenchymal stem cells (MSCs) are a type of multipotent adult stem cells that have the potential to form different cell types, including adipocytes, osteocytes, chondrocytes, cardiomyocytes and neurons (1). Human umbilical cord MSCs (hUCMSCs), a novel type of MSCs, have various phenotypes and characteristics in common with MSCs (2). The umbilical cords, particularly the Wharton's jelly tissues are rich in hUCMSCs (1). hUCMSCs have been broadly studied in the field of transplant therapy (2). Compared with other types of MSCs, hUCMSCs are easily obtained and the method used to isolate them is not traumatic to the donors (3) and the umbilical cord is a rich and easily available source of hUCMSCs (3). The benefits of hUCMSCs has led to their wide use in transplantation medicine. Previous studies have revealed that hUCMSCs have been used to treat neurodegeneration, neuronal injury, cardiac infarction, diabetes mellitus, kidney and lung injury (4-9).

The most important factor determining the therapeutic efficiency of the transplanted hUCMSCs is their proliferative ability in vitro or in vivo in the recipient bodies (10). High proliferative ability ensures a higher hUCMSCs survival rate in the host organs or tissues following the transplantation. Previous studies indicated that additional supplements of the growth factors, such as insulin-like growth factor 1 (IGF-1), fibroblast growth factor, epidermal growth factor, basic fibroblast growth factor (bFGF) and platelet-derived growth factor may promote the proliferation of MSCs (11-13).

IGF-1 is a 70-amino acid protein in humans and has multiple biological functions in cell physiology. IGF-1, binding to its receptor (IGF-1R), mediates the phosphoinositide 3-kinase (PI3K)/protein kinase B (Akt)/mechanistic target of rapamycin (mTOR) and mitogen-activated protein kinase (MAPK)/extracellular-signal regulated kinase (ERK) signaling pathways that contribute to regulation of cell proliferation, differentiation and apoptosis (14-17). Previous 
studies indicated that MSCs are able to secrete growth factors, including IGF-1, bFGF, hepatocyte growth factor and vascular endothelial growth factor, or increase the expression levels of these growth factors in the host cells, tissues or organs following transplantation (18-20).

The growth factors secreted by the transplanted hUCMSCs have been demonstrated to stimulate growth of the host cells in the recipients. Imberti et al (21) reported that IGF-1 secreted by bone marrow MSCs promoted proliferation of proximal tubular epithelial cells (PTEC) and inhibited cisplatin-induced PTEC apoptosis in the in vitro co-culture state (21). Blocking IGF-1R with a specific antibody attenuated PTEC proliferation and increased their apoptotic rate (21). These findings were confirmed by Morigi et al (22) in an in vivo study, which revealed that the release of IGF-1 from the transplanted MSCs may stimulate tubular cell proliferation, limit renal cell apoptosis and accelerate mice recovery from acute renal injury (22). A previous study indicated that the transplanted MSCs stimulated the osteoblast proliferation and the formation of new bone through paracrine IGF-1 and promoted their differentiation into osteoblasts through the autocrine IGF-1 in the recipients (23). These previous findings suggest that MSCs may affect their own physiological functions via autocrine IGF-1. Additionally, a previous in vitro study also indicated that treatment with exogenous IGF-1 may increase MSC viability (13). Therefore, the present study hypothesized that the autocrine IGF-1 may affect the viability of MSCs. In order to verify this hypothesis, hUCMSCs were treated with $\alpha$ IR-3, a specific IGF-1R-blocking antibody, to block the action of the autocrine IGF-1. Subsequently cell viability, cell cycle and apoptosis of hUCMSCs were quantified and the underlying molecular mechanisms were investigated.

\section{Materials and methods}

hUCMSCs culture. A total of 12 umbilical cords from full-term deliveries were obtained from the Affiliated Hospital of Guizhou Medical University (Guiyang, China) from January-December 2012. The gender ratio of the collected umbilical cords was 1:1. Written informed consent was obtained from parents and the experiments were performed and approved by the Ethical Committee of Guizhou Medical University (Guiyang, China). The isolation and culture of hUCMSCs was performed as previously described (24). The umbilical cords were washed twice with pre-cooled PBS at $4^{\circ} \mathrm{C}$, the umbilical vessels were removed and the Wharton's jelly was minced into $\sim 2.5 \mathrm{~mm}^{3}$ sections. The small sections were plated in 100-mm dishes (Sigma-Aldrich; Merck Millipore, Darmstadt, Germany) in 5-mm wide gaps and cultured in Dulbecco's modified Eagle's medium/Nutrient mixture F12 (DMEM/F12; GE Healthcare Life Sciences, Chalfont, UK) supplemented with $20 \%$ fetal bovine serum (FBS; GE Healthcare Life Sciences), $100 \mathrm{U} / \mathrm{ml}$ penicillin (Beyotime Institute of Biotechnology, Beijing, China) and $100 \mathrm{mg} / \mathrm{ml}$ streptomycin (Beyotime Institute of Biotechnology) at $37^{\circ} \mathrm{C}$ with $5 \% \mathrm{CO}_{2}$. Cells at $85 \%$ confluence were digested with $0.25 \%$ trypsin (GE Healthcare Life Sciences) and transferred into $75 \mathrm{~cm}^{2}$ cell culture flasks (Sigma-Aldrich; Merck Millipore) and cultured with DMEM/F12 medium with $10 \%$ FBS at $37^{\circ} \mathrm{C}$ with $5 \% \mathrm{CO}_{2}$.
Treatment groups. The passage 4 of hUCMSCs was plated into 6 -well $\left(5 \times 10^{4}\right.$ cells/well) or 24 -well $\left(1 \times 10^{4}\right.$ cells/well) plates and randomly divided into two groups: i) Control group; and ii) experimental group. The cells were treated with $5 \mu \mathrm{g} / \mathrm{ml}$ aIR-3 (cat. no. MABS192; Merck Millipore) in the experimental group and without $\alpha$ IR-3 in the control group for $24 \mathrm{~h}$. Cell viability, apoptosis, cell cycle and levels of Akt/glycogen synthase kinase (GSK)-3 $\beta$ activation were subsequently quantified.

Immunocytochemistry staining. hUCMSCs $\left(1 \times 10^{4}\right)$ cultured on coverslips were fixed in $4 \%$ paraformaldehyde for $10 \mathrm{~min}$ and permeabilized with $0.1 \%$ Triton $\mathrm{X}-100$ for $10 \mathrm{~min}$ at room temperature. Following washing with PBS, the cells were incubated with $3 \%$ hydrogen peroxide for $10 \mathrm{~min}$ at room temperature to block the endogenous peroxidase activity. Following washing twice with PBS, the cells were blocked with $10 \%$ goat serum (Wuhan Boster Biological Technology, Ltd., Wuhan, China) for $20 \mathrm{~min}$ and then incubated with rabbit anti-human polyclonal IGF-1 antibody (cat. no. ab9572; 1:200; Abcam, Cambridge, MA, USA; ) and rabbit anti-human polyclonal IGF-1 receptor $\beta$ antibody (cat. no. 3027; 1:200; Cell Signaling Technology, Inc., Danvers, MA, USA) overnight at $4^{\circ} \mathrm{C}$. The cells were washed with PBS three times and then incubated with horseradish peroxidase (HRP)-conjugated goat anti-rabbit secondary antibody (cat. no. A0208; 1:5,000; Beyotime Institute of Biotechnology) for $30 \mathrm{~min}$ at room temperature. The cells were washed four times with PBS and incubated with streptavidin biotin complex (SABC) solution (Beyotime Institute of Biotechnology) for $20 \mathrm{~min}$ at room temperature and subsequently washed with PBS four times. The cells were incubated with $100 \mu 1$ 3,3'-diaminobenzidine substrate solution (Beyotime Institute of Biotechnology) for $5 \mathrm{~min}$ and observed under an inverted microscope (NIKON TS100; Nikon Corporation, Tokyo, Japan), followed by dehydration with $95 \%$ ethanol, clearing with xylene and sealing with neutral gum (Beyotime Institute of Biotechnology).

Cell cycle analysis. Following treatment with $\alpha$ IR3, hUCMSCs were digested with $0.25 \%$ trypsin, collected, washed with pre-cold PBS and fixed with cold $70 \%$ ethanol. The cells were washed with pre-cold PBS three times, resuspended in $500 \mu \mathrm{l}$ PBS and treated with $50 \mu \mathrm{l}$ of RNase-A $(100 \mu \mathrm{g} / \mathrm{ml}$; Sigma-Aldrich; Meck Milipore) and $200 \mu \mathrm{l}$ of propidium iodide $(50 \mu \mathrm{g} / \mathrm{ml}$; Beyotime Institute of Biotechnology) solution with $0.1 \%$ Triton-X 100 in the dark. Cell cycle was analyzed using a flow cytometer at $488 \mathrm{~nm}$ (BD Biosciences, San Jose, CA, USA).

Quantification of cell apoptosis. Apoptosis of hUCMSCs was quantified using a flow cytometry assay using a Dead Cell Apoptosis kit with fluorescein isothiocyanate-Annexin V/(Invitrogen; Thermo Fisher Scientific, Inc., Waltham, MA, USA) following the manufacturer's protocol. Analysis of apoptosis (Annexin V positivity) was conducted using a flow cytometer at 488 and $535 \mathrm{~nm}$.

Western blotting. Proteins were extracted from the treated hUCMSCs using RIPA lysis buffer (Sigma-Aldrich; Merck Millipore) supplemented with protease inhibitor 
A

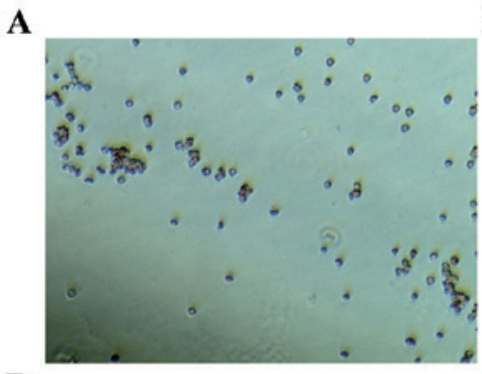

D

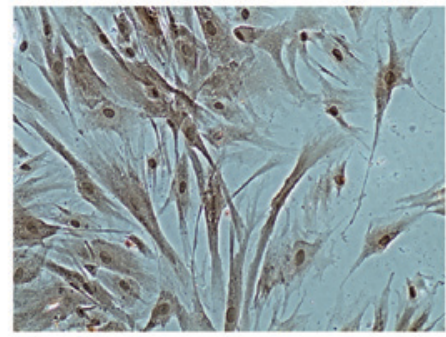

B

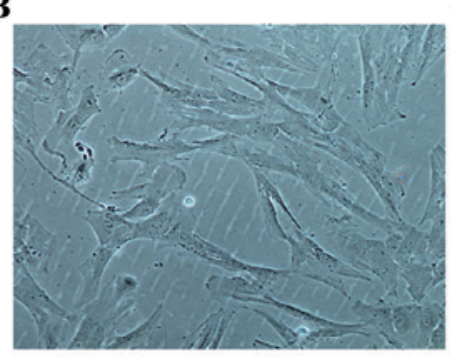

E

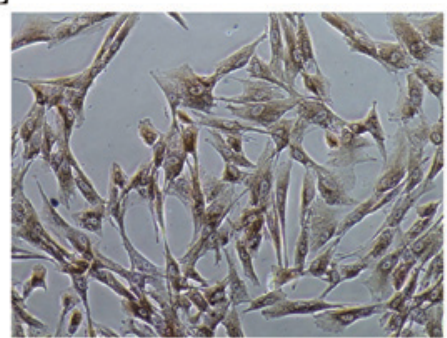

C

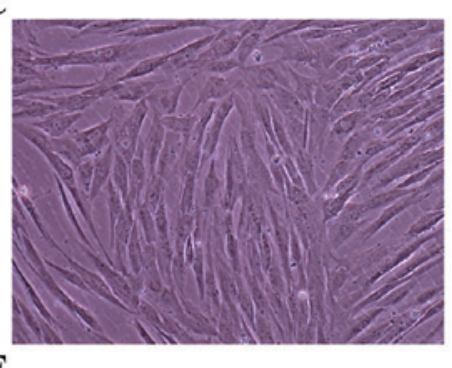

F

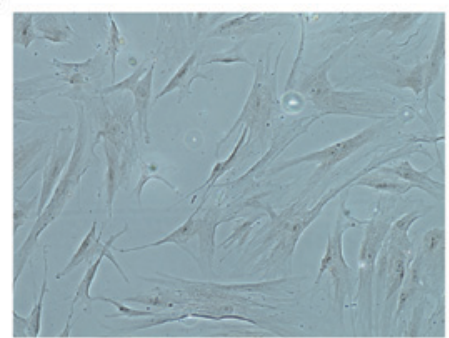

Figure 1. Morphology of hUCMSCs and the expression of IGF-1 and IGF-1R in hUCMSCs. (A) Morphology of primary hUCMSCs was observed (A) 2 and (B) 7 days after the Wharton's jelly tissues $\left(2 \mathrm{~mm}^{3}\right)$ were plated. (C) Morphology of passage 4 hUCMSCs 2 days after plating. (D) Immunochemistry staining for IGF-1 expression in hUCMSCs, particularly in the nuclei. (E) Immunochemistry staining revealed that expression of IGF-1R was primarily evident on the membrane of hUCMSCs and was absent in the nuclei. (F) Staining of the negative control group. Magnification, x200. hUCMSCs, human umbilical cord mesenchymal stem cells; IGF-1; insulin-like growth factor-1; IGF-1R, insulin-like growth factor-1 receptor.

(Sigma-Aldrich; Merck Millipore), phosphatase inhibitor (Sigma-Aldrich; Merck Millipore) and phenylmethylsulfonyl fluoride (PMSF; Sigma-Aldrich; Merck Millipore). The protein concentration was quantified using a bicinchoninic acid protein assay kit (Beyotime Institute of Biotechnology). Proteins (30 $\mu \mathrm{g} /$ lane) were diluted in $2 \mathrm{X}$ SDS-PAGE protein loading buffer (Beyotime Institute of Biotechnology), heated at $95^{\circ} \mathrm{C}$ for $5 \mathrm{~min}$, loaded into $10 \%$ SDS-PAGE gel (Beyotime Biotechnology) and separated by electrophoresis. Following electrophoresis, the proteins were transferred onto polyvinylidene difluoride membranes (EMD Millipore, Billerica, MA, USA). The membranes were blocked with 5\% non-fat milk in Tris-buffered saline with Tween-20 (TBST) for $4 \mathrm{~h}$ at room temperature and subsequently incubated with rabbit anti-human phosphorylated (p)-Akt polyclonal antibody (cat. no. ab18206; 1:1,000; Abcam), rabbit anti-human p-glycogen synthase kinase $3 \beta$ (GSK-3 $\beta$ ) polyclonal antibody (cat. no. 9336; 1:1,000; Cell Signaling Technology, Inc.), rabbit anti-human p21 polyclonal antibody (cat. no. ab7960; 1:1,000; Abcam), rabbit anti-human cyclin D1 polyclonal antibody (cat. no. 2922; 1:1,000; Cell Signaling Technology, Inc.), rabbit anti-human p-p70 S6 kinase (P70S6K) polyclonal antibody (cat. no. 9025; 1:1,000; Cell Signaling Technology, Inc.), rabbit anti-human p-ERK1/2 monoclonal antibody (cat. no. 4370; 1:1,000; Cell Signaling Technology, Inc.) in blocking solution at $4^{\circ} \mathrm{C}$ overnight. The blots were washed 3 times with TBST and incubated with HRP-conjugated goat anti-rabbit secondary antibody (cat. no. BA1054; 1:5,000, Wuhan Boster Biological Technology) in a blocking solution for $1 \mathrm{~h}$ at room temperature. The immunoreactive bands were washed with TBST, visualized with western blotting enhanced chemiluminescence reagent (EMD Millipore) and subsequently exposed to X-ray film (Thermo Fisher Scientific, Inc.). The blots were normalized to the expression of $\beta$-actin, which was detected by the same blots through washing with a stripping buffer
Table I. Cell viability of human umbilical cord mesenchymal stem cells following treatment with $5 \mu \mathrm{g} / \mathrm{ml} \alpha \mathrm{IR}-3$ for $24 \mathrm{~h}$.

\begin{tabular}{ll}
\hline Group & Cell viability \\
\hline Control & $0.591 \pm 0.111$ \\
$\alpha \mathrm{IR}-3(5 \mu \mathrm{g} / \mathrm{ml})$ & $0.431 \pm 0.104^{\mathrm{a}}$
\end{tabular}

Cell viability was determined by quantifying MTT absorbance at $570 \mathrm{~nm}$. Data are presented as the mean \pm standard deviation. ${ }^{\mathrm{a}} \mathrm{P}<0.05$ vs. control group. $n=6$.

(Beyotime Institute of Biotechnology) and subsequent incubation with rabbit anti-mouse $\beta$-actin polyclonal antibody (cat. no. ab8227; 1:2,000; Abcam). All protein bands were quantified by densitometry using ImageJ software (version 1.48h3; National Institutes of Health, Bethesda, MD, USA).

Statistical analysis. Statistical analysis was performed using SPSS version 15.0 software (SPSS, Inc., Chicago, IL, USA). Data are presented as the mean \pm standard deviation from 4-6 independent experiments. Univariate comparisons of means were evaluated using the Student t-test. $\mathrm{P}<0.05$ was considered to indicate a statistically significant difference.

\section{Results}

Morphology of hUCMSCs and expression levels of IGF-1 and IGF-1R. The morphology of primary and passaged hUCMSCs was determined at 2 and 7 days after the Wharton's jelly sections were plated. As presented in Fig. 1A, round cells dissociated from the Wharton's jelly sections and attached to the bottom of the culture dishes 2 days after the small sections were plated. By day 7, cells assumed triangular 

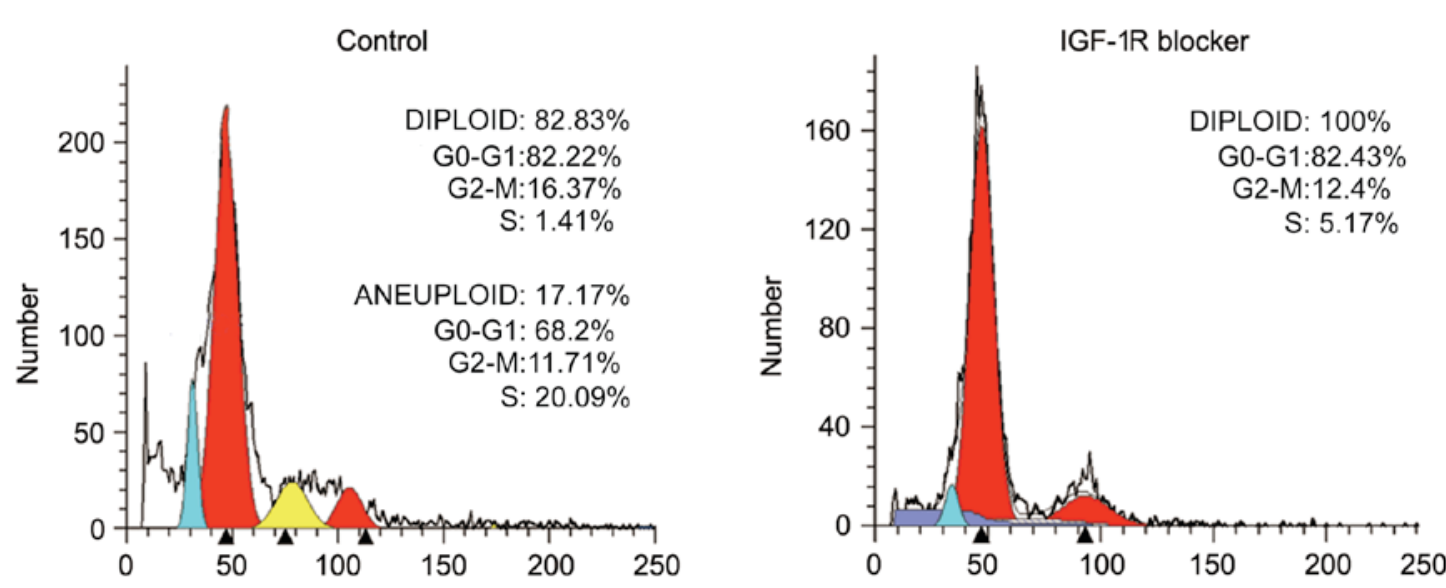

Figure 2. Cell cycle analysis revealed that treatment with an IGF-1R blocker, $\alpha$ IR-3, markedly reduced the number of cells in the G2/M phase. Red indicates diploid cells; dark blue, debris; yellow, aneuploid; light blue, cell death. Data presented are from four separate experiments. IGF-1; insulin-like growth factor-1.
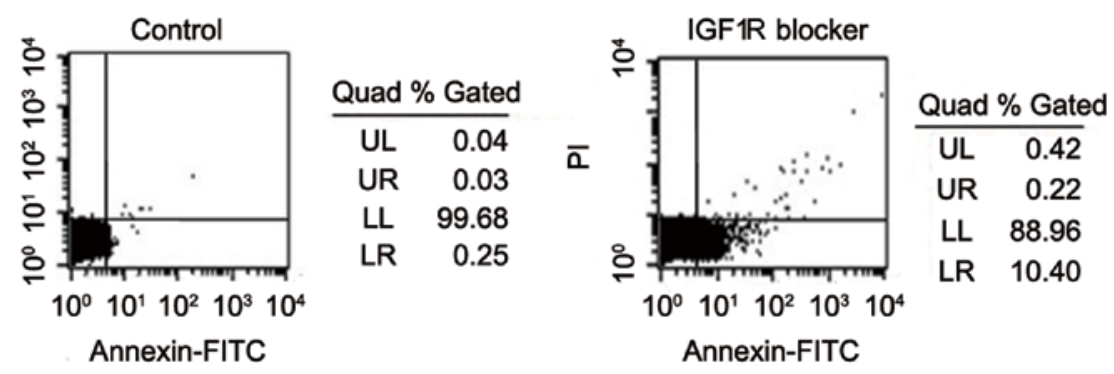

Figure 3. Flow cytometry assay revealed cell apoptosis (Annexin $\mathrm{V}$ positive cells) in human umbilical cord mesenchymal stem cells following treatment with $5 \mu \mathrm{g} / \mathrm{ml} \alpha$ IR-3, specific IGF-1R blocking antibody, for $24 \mathrm{~h}$. The Annexin V positivity was higher in the experimental group comapred with the control group. Data presented are from five separate experiments. IGF1R, insulin-like growth factor-1 receptor.

and spindle shape and a number of cells had long dendrites (Fig. 1B). Cells at passage 4 exhibited long spindle shape and upon reaching confluence, formed a pattern similar to a whirlpool (Fig. 1C). Immunocytochemistry staining revealed that IGF-1 was expressed in hUCMSCs, particularly in the nuclei (Fig. 1D). IGF-1R was also positively expressed in hUCMSCs, primarily located on the membrane and absent in the nuclei (Fig. 1E).

Blockade of autocrine IGF-1 reduces hUCMSCs cell viability. The present study quantified cell viability using an MTT assay. As presented in Table I, treatment with the IGF-1R-specific blocker $\alpha$ IR-3 for $24 \mathrm{~h}$ significantly reduced the hUCMSCs cell viability when compared with the control group $(\mathrm{P}<0.05)$. Additionally, cell cycle analysis revealed that the number of cells in the $\mathrm{G} 2 / \mathrm{M}$ phase was reduced in the experimental group compared with the control group, which also indicated a reduced proliferation of hUCMSCs following treatment with $\alpha$ IR-3 (Fig. 2).

Blockade of autocrine IGF-1 induces hUCMSCs apoptosis. Cell apoptosis was quantified by analysis of Annexin $\mathrm{V}$ activity using flow cytometry. The increase of Annexin $\mathrm{V}$ activity indicated an early stage of apoptosis (25). As presented in Fig. 3, treatment with the IGF-1R-specific blocker, $\alpha$ IR-3, markedly increased Annexin V positivity (from $0.25 \%$ in the control group to $10.40 \%$ in the experimental group).
Effect of blockade of autocrine IGF-1 on the expression levels of p-Akt, $p$-ERK1/2, p-Gsk-3b, p-P70S6K, cyclin D1 and 21 in hUCMSCs. Previous studies have reported that the binding of IGF-1 to its receptor may mediate the activation of the PI3K/Akt and MAPK/ERK signaling pathways $(15,16)$. The findings of the present study revealed that treatment with the IGF-1R-specific blocker $\alpha$ IR-3 significantly reduced the expression levels of $\mathrm{p}-\mathrm{Akt}, \mathrm{p}-\mathrm{Gsk}-3 \beta$ and $\mathrm{p}-\mathrm{P} 70 \mathrm{~S} 6 \mathrm{~K}(\mathrm{P}<0.05$; Fig. 4; Table II), However, no significant difference was identified in p-ERK1/2 expression when the experimental group was compared with the control group ( $\mathrm{P}>0.05$; Fig. 4; Table II). These findings indicated that the effect of autocrine IGF-1 on hUCMSCs cell viability may be due to the activation of the Akt/Gsk-3ß/P70S6K signaling pathway; however, not the activation of MAPK/ERK signaling pathway. In addition, treatment with $\alpha$ IR-3 also significantly reduced cyclin D1 expression levels and increased $\mathrm{p} 21$ expression levels $(\mathrm{P}<0.05$; Fig. 4; Table II). These two proteins are important factors determining cell viability and apoptosis (26).

\section{Discussion}

A previous report has suggested that MSCs are able to secrete IGF-1 (18). To the best of our knowledge, this is the first study to investigate whether MSCs may be able to alter their own proliferation through autocrine IGF-1. Therefore, the present study examined the effect of autocrine IGF-1 on cell viability 
Table II. Protein expression values of p-Akt, p-ERK1/2, p-GSK-3 $\beta$, p-P70S6K, cyclin D1 and p21, relative to $\beta$-actin in human umbilical cord mesenchymal stem cells following treatment with $5 \mu \mathrm{g} / \mathrm{ml} \alpha \mathrm{IR}-3$ for $24 \mathrm{~h}$.

\begin{tabular}{lcc}
\hline Target proteins & \multicolumn{1}{c}{ Control } & $\alpha \mathrm{IR}-3(5 \mu \mathrm{g} / \mathrm{ml})$ \\
\hline p-Akt & $0.3017 \pm 0.0198$ & $0.1121 \pm 0.0078^{\mathrm{a}}$ \\
p-ERK1 & $0.3321 \pm 0.0338$ & $0.3977 \pm 0.0206$ \\
p-ERK2 & $0.5605 \pm 0.0303$ & $0.6012 \pm 0.0382$ \\
p-GSK-3 & $0.5589 \pm 0.0417$ & $0.2769 \pm 0.0154^{\mathrm{a}}$ \\
p-P70S6K & $0.8187 \pm 0.05074$ & $0.4139 \pm 0.0215^{\mathrm{a}}$ \\
Cyclin D1 & $0.8302 \pm 0.0412$ & $0.3241 \pm 0.0146^{\mathrm{a}}$ \\
p21 & $0.1384 \pm 0.0079$ & $0.2983 \pm 0.0131^{\mathrm{a}}$ \\
\hline
\end{tabular}

Data are presented as the mean \pm standard deviation. ${ }^{\text {a }} \mathrm{P}<0.05$ vs. control group. $n=4$. $\alpha$ IR-3, specific insulin-like growth factor-1 receptor blocking antibody; $\mathrm{p}$, phosphorylated; Akt, protein kinase $\mathrm{B}$; ERK1/2, extracellular-signal regulated kinase $1 / 2$; GSK-3 $\beta$, glycogen synthase kinase 3ß; P70S6K, p70 S6 kinase.

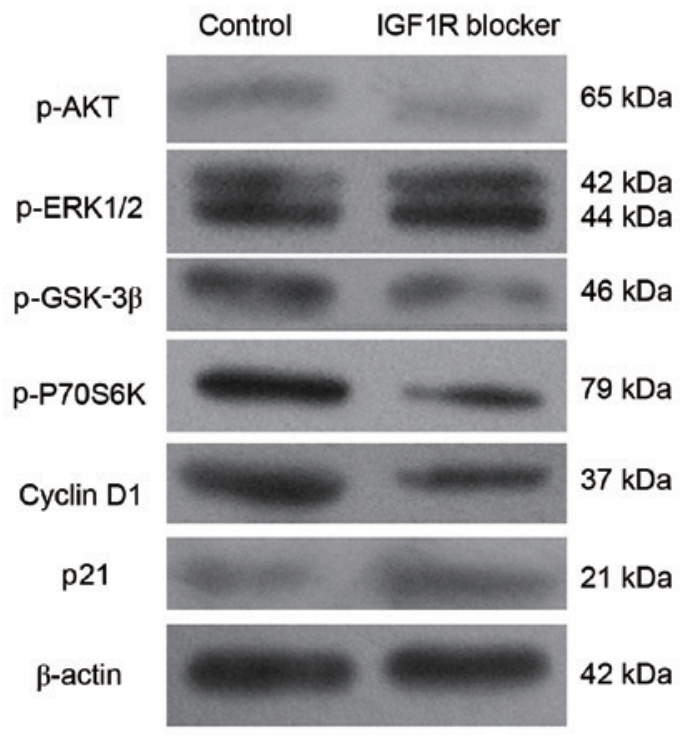

Figure 4. Western blotting assay was performed to determine the protein expression levles of p-AKT, p-ERK1/2, p-GSK-3 $\beta$, p-p70S6K, cyclin D1 and p21 in the experimental and control groups. Data presented are from four separate experiments. p, phosphorylated; Akt, protein kinase B; ERK1/2, extracellular-signal regulated kinase 1/2; GSK-3ß; P70S6K, p70 S6 kinase.

and apoptosis of hUCMSCs. The expression levels of IGF-1 and IGF-1R in hUCMSCs were quantified and it was determined that both were expressed in hUCMSCs. The hUCMSCs were treated with $5 \mu \mathrm{g} / \mathrm{ml} \alpha \mathrm{IR}-3$ (an IGF-1R-specific blocker) for $24 \mathrm{~h}$ in order to block the autocrine IGF-1. It was determined that treatment with $\alpha$ IR-3 significantly reduced cell viability and increased apoptosis of hUCMSCs. Additionally, cell cycle analysis revealed that the number of cells in the G2/M phase was reduced in the experimental group compared with the control group, which also indicated a low viability of hUCMSCs following treatment with $\alpha$ IR-3. Treatment with $\alpha$ IR-3 significantly reduced p-Akt, p-Gsk-3 $\beta$, p-P70S6K and cyclin D1 expression levels, whereas the expression of p21 was significantly increased in the experimental group compared with the control. However, $\alpha$ IR-3 treatment did not significantly affect p-ERK1/2 expression levels. These findings indicated that the mechanism by which autocrine IGF-1 altered hUCMSCs cell viability and apoptosis of may be via the activation of the Akt/Gsk-33/P70S6K signaling pathway.

The human umbilical cord is a promising source of MSCs and the transplantation of hUCMSCs has revealed a novel area for stem cell therapy (27). hUCMSCs may be readily isolated and the collection procedure is painless to the donors, unlike bone marrow-derived MSCs. Additionally, hUCMSCs have the increased self-renewal properties and potentials to differentiate into multiple cell lineages (27). These unique characteristics allow for hUCMSCs to be widely applied in regenerative medicine. Their proliferative ability is an important factor affecting the efficiency of MSCs-based cell transplantation therapy.

IGF-1 is a peptide hormone that has been demonstrated to stimulate the growth of several of cell lineages in vivo and in vitro. IGF-1 exerts the majority of its effect via binding to its receptor IGF-1R (28). Previous studies suggested that MSCs may be able to secrete a series of growth factors, including IGF-1 (18-20). The current study determined that IGF-1 and IGF-1R are expressed in hUCMSCs. This suggested that the auto-secreted IGF-1 by hUCMSCs has the potential to affect cell viability of hUCMSCs by binding to the membrane-bound IGF-1R and subsequently initiating the downstream intracellular signals. The present study used $\alpha$ IR-3, an IGF-1R-specific antibody, to block the autocrine IGF-1 binding to IGF-1R. As expected, the blockade of the autocrine IGF-1 with $\alpha$ IR-3 significantly reduced cell viability of hUCMSCs, and reduced the number of G2/M phase cells. Additionally, blocking the autocrine IGF-1 also markedly increased the hUCMSCs apoptotic rate, which indirectly indicated a low cell viability following treatment with $\alpha$ IR-3. IGF-1 is a critical stimulator of cell proliferation and a potent inhibitor of programmed cell death $(28,29)$. Blocking autocrine IGF-1 inhibited cell growth and initiated apoptosis of hUCMSCs.

The binding of IGF-1 to IGF-1R may lead to the activation of critical downstream targets, through the Akt/mTOR and MAPK/ERK signaling pathways, which mediate cell cycle progression and prevent cell apoptosis (30). The present study determined that blockade of the autocrine IGF-1 markedly reduced the expression of $\mathrm{p}$-Akt; however, the expression of p-ERK1/2 was not affected. Previous studies have determined that IGF-1 is a potent natural activator of the Akt signaling pathway $(28,30)$. GSK-3 $\beta$ is one of the downstream signals of Akt. The findings of the present study revealed that the blockade of the autocrine IGF-1 significantly inhibited the expression of $\mathrm{p}-\mathrm{GSK}-3 \beta$. These findings indicated that the inhibitory effect of blocking autocrine IGF-1 on cell viability of hUCMSCs may depend on inactivation of the Akt/GSK-3 $\beta$ signaling pathway, not the ERK1/2 signaling pathway. A recent study also reported that inhibition of Akt/GSK-3 $\beta$ signaling reduced cell viability and induced apoptosis in colorectal cancer cell lines (31). In addition, the present study also determined that blockade of the autocrine IGF-1 reduced the expression of $\mathrm{p}-\mathrm{P} 70 \mathrm{~S} 6 \mathrm{~K}$. P70S6K is a serine/threonine kinase that contributes to the downstream signaling in the PI3K/Akt//GSK-3 $\beta$ pathway (32). P70S6K may promote cell 
cycle progression and cell growth through regulating the organization of cytoskeleton (33).

Cell cycle proteins, such as cell division cycle 42 and cyclins are important regulators for the activation of P70S6K (34). The current study determined that blockade of the autocrine IGF-1 reduced cyclin D1 expression and increased p21 expression. These findings confirmed the low viability of hUCMSCs following treatment with the IGF-1R blocker, $\alpha$ IR-3. Cyclin D1 is important for cell cycle progression, as it controls the progression from G1 to S phase (35). P21 is a potent cyclin-dependent kinase inhibitor, which binds of cyclin-cyclin-dependent kinase complexes, suppresses their activity and therefore inhibits cell cycle progression at the G1 and $S$ phase (36).

In conclusion, the present study demonstrated that hUCMSCs may affect their own viability through autocrine IGF-1. Blocking the autocrine IGF-1 using a IGF-1R-specific blocker markedly reduced hUCMSCs viability and induced apoptosis. The information presented in the current study provides evidence that the self-characteristics of MSCs may be used to regulate their physiological functions.

\section{Acknowledgements}

The present study was supported by grants from the National Natural Science Foundation of China (grant nos. 81160099 and 31401246; Beijing, China).

\section{References}

1. Watson N, Divers R, Kedar R, Mehindru A, Mehindru A Borlongan MC and Borlongan CV: Discarded Wharton jelly of the human umbilical cord: A viable source for mesenchymal stromal cells. Cytotherapy 17: 18-24, 2015.

2. Li DR and Cai JH: Methods of isolation, expansion, differentiating induction and preservation of human umbilical cord mesenchymal stem cells. Chin Med J (Engl) 125: 4504-4510, 2012.

3. Li T, Xia M, Gao Y, Chen Y and Xu Y: Human umbilical cord mesenchymal stem cells: An overview of their potential in cell-based therapy. Expert Opin Biol Ther 15: 1293-1306, 2015.

4. Yang H, Xie Z, Wei Z, Yang H, Yang S, Zhu Z, Wang P, Zhao C and Bi J: Human umbilical cord mesenchymal stem cell-derived neuron-like cells rescue memory deficits and reduce amyloid-beta deposition in an A $\beta P P / P S 1$ transgenic mouse model. Stem Cell Res Ther 4: 76, 2013.

5. Cui B, Li E, Yang B and Wang B: Human umbilical cord blood-derived mesenchymal stem cell transplantation for the treatment of spinal cord injury. Exp Ther Med 7: 1233-1236, 2014.

6. Santos Nascimento D, Mosqueira D, Sousa LM, Teixeira M, Filipe M, Resende TP, Araújo AF, Valente M, Almeida J, Martins JP, et al: Human umbilical cord tissue-derived mesenchymal stromal cells attenuate remodeling after myocardial infarction by proangiogenic, antiapoptotic, and endogenous cell-activation mechanisms. Stem Cell Res Ther 5: 5, 2014.

7. Wang G, Li Y, Wang Y, Dong Y, Wang FS, Ding Y, Kang Y and $\mathrm{Xu} \mathrm{X}$ : Roles of the co-culture of human umbilical cord Wharton's jelly-derived mesenchymal stem cells with rat pancreatic cells in the treatment of rats with diabetes mellitus. Exp Ther Med 8 : 1389-1396, 2014.

8. Chen Y, Qian H, Zhu W, Zhang X, Yan Y, Ye S, Peng X, Li W and $\mathrm{Xu} \mathrm{W}$ : Hepatocyte growth factor modification promotes the amelioration effects of human umbilical cord mesenchymal stem cells on rat acute kidney injury. Stem Cells Dev 20: 103-113, 2011.

9. Min F, Gao F, Li Q and Liu Z: Therapeutic effect of human umbilical cord mesenchymal stem cells modified by angiotensin-converting enzyme 2 gene on bleomycin-induced lung fibrosis injury. Mol Med Rep 11: 2387-2396, 2015.
10. Lee S, Choi E, Cha MJ and Hwang KC: Cell adhesion and long-term survival of transplanted mesenchymal stem cells: A prerequisite for cell therapy. Oid Med Cell Longev 2015: 632902, 2015.

11. Tsutsumi S, Shimazu A, Miyazaki K, Pan H, Koike C, Yoshida E, Takagishi K and Kato Y: Retention of multilineage differentiation potential of mesenchymal cells during proliferation in response to FGF. Biochem Biophys Res Commun 288: 413-419, 2011.

12. Chieregato K, Castegnaro S, Madeo D, Astori G, Pegoraro M and Rodeghiero F: Epidermal growth factor, basic fibroblast growth factor and platelet-derived growth factor-bb can substitute for fetal bovine serum and compete with human platelet-rich plasma in the ex vivo expansion of mesenchymal stromal cells derived from adipose tissue. Cytotherapy 13: 933-943, 2011.

13. Huat TJ, Khan AA, Pati S, Mustafa Z, Abdullah JM and Jaafar H: IGF-1 enhances cell proliferation and survival during early differentiation of mesenchymal stem cells to neural progenitor-like cells. BMC Neurosi 15: 91, 2014.

14. Bertrand FE, Steelman LS, Chappell WH, Abrams SL, Shelton JG, White ER, Ludwig DL and McCubrey JA: Synergy between an IGF-1R antibody and Raf/MEK/ERK and PI3K/Akt/mTOR pathway inhibitors in suppressing IGF-1R-mediated growth in hematopoietic cells. Leukemia 20: 1254-1260, 2006.

15. Lau MT and Leung PC: The PI3K/Akt/mTOR signaling pathway mediates insulin-like growth factor 1-induced E-cadherin down-regulation and cell proliferation in ovarian cancer cells. Cancer Lett 326: 191-198, 2012.

16. Tao Y, Zhou X, Liang C, Li H, Han B, Li F and Chen Q: TGF- $\beta 3$ and IGF-1 synergy ameliorates nucleus pulposus mesenchymal stem cell differentiation towards the nucleus pulposus cell type through MAPK/ERK signaling. Growth Factors 33: 326-336, 2015.

17. Yang X, Wei A, Liu Y, He G, Zhou Z and Yu Z: IGF-1 protects retinal ganglion cells from hypoxia-induced apoptosis by activating the Erk-1/2 and Akt pathways. Mol Vis 19: 1901-1912, 2013.

18. Zhu SF, He YL and Fu XF: Biological features and ultrastructure of human umbilical cord mesenchymal stem cells. Zhongguo Yi Xue Ke Xue Yuan Xue Bao 33: 382-386, 2011 (In Chinese).

19. Yamahara K, Harada K, Ohshima M, Ishikane S, Ohnishi S, Tsuda H, Otani K, Taguchi A, Soma T, Ogawa H, et al: Comparison of angiogenic, cytoprotective, and immunosuppressive properties of human amnion- and chorion-derived mesenchymal stem cells. PLoS One 9: e88319, 2014.

20. Shalaby RH, Rashed LA, Ismaail AE, Madkour NK and Elwakeel SH: Hematopoietic stem cells derived from human umbilical cord ameliorate cisplatin-induced acute renal failure in rats. Am J Stem Cells 3: 83-96, 2014.

21. Imberti B, Morigi M, Tomasoni S, Rota C, Corna D, Longaretti L, Rottoli D, Valsecchi F, Benigni A, Wang J, et al: Insulin-like growth factor-1 sustains stem cell mediated renal repair. J Am Soc Nephrol 18: 2921-2928, 2007.

22. Morigi M, Introna M, Imberti B, Corna D, Abbate M, Rota C, Rottoli D, Benigni A, Perico N,Zoja C, et al: Human bone marrow mesenchymal stem cells accelerate recovery of acute renal injury and prolong survival in mice. Stem Cells 26: 2075-2082, 2008.

23. Granero-Moltó F, Myers TJ, Weis JA, Longobardi L, Li T, Yan Y, Case N, Rubin J and Spagnoli A: Mesenchymal stem cells expressing insulin-like growth factor-I (MSCIGF) promote fracture healing and restore new bone formation in Irs1 knockout mice: Analyses of MSCIGF autocrine and paracrine regenerative effects. Stem Cells 29: 1537-1548, 2011.

24. Zhang F, Hong Y, Liang W, Ren T, Jing S and Lin J: Co-culture with Sertoli cells promotes proliferation and migration of umbilical cord mesenchymal stem cells. Biochem Biophys Res Commun 427: 86-90, 2012.

25. Zhang G, Gurtu V, Kain SR and Yan G: Early detection of apoptosis using a fluorescent conjugate of annexin V. Biotechniques 23: 525-531, 1997.

26. Wang J, Zheng T, Chen X, Song X, Meng X, Bhatta N, Pan S, Jiang $\mathrm{H}$ and Liu L: MDM2 antagonist can inhibit tumor growth in hepatocellular carcinoma with different types of p53 in vitro. J Gastroenterol Hepatol 26: 371-377, 2011.

27. Ding DC, Chang YH, Shyu WC and Lin SZ: Human umbilical cord mesenchymal stem cells: A new era for stem cell therapy. Cell Transplant 24: 339-347, 2015.

28. Ashare A, Nymon AB, Doerschug KC, Morrison JM, Monick MM and Hunnighake GW: Insulin-like growth factor-1 improves survival in sepsis via enhanced hepatic bacterial clearance. Am J Respir Crit Care Med 178: 149-157, 2008. 
29. Galvan V, Logvinova A, Sperandio S, Ichijo H and Bredesen DE: Type 1 insulin-like growth factor receptor (IGF-IR) signaling inhibits apoptosis signal-regulating kinase 1 (ASK1). J Biol Chem 278: 13325-13332, 2003.

30. Shelton JG, Steelman LS, White ER and McCubrey JA: Synergy between PI3K/Akt and Raf/MEK/ERK pathways in IGF-1R mediated cell cycle progression and prevention of apoptosis in hematopoietic cells. Cell Cycle 3: 372-379, 2004.

31. Wang G, Feng CC, Chu SJ, Zhang R, Lu YM, Zhu JS and Zhang J Toosendanin inhibits growth and induces apoptosis in colorectal cancer cells through suppression of AKT/GSK-3 $\beta / \beta$-catenin pathway. Int J Oncol 47: 1767-1774, 2015.

32. Park ES, Kang DH, Yang MK, Kang JC, Jang YC, Park JS, Kim SK and Shin HS: Cordycepin, 3'-deoxyadenosine, prevents rat hearts from ischemia/reperfusion injury via activation of Akt/GSK-3 $3 /$ p70S6K signaling pathway and HO-1 expression. Cardiovasc Toxicol 14: 1-9, 2014.
33. Wang X, Khaidakov M, Ding Z, Dai Y, Mercanti F and Mehta JL: LOX-1 in the maintenance of cytoskeleton and proliferation in senescent cardiac fibroblasts. J Mol Cell Cardiol 60: 184-190, 2013.

34. Chou MM, Masuda-Robens JM and Gupta ML: Cde 42 promotes G1 progression through p70 S6 kinase-mediated induction of cyclin E expression. J Biol Chem 278: 35241-35247, 2003.

35. Resnitzky D, Gossen M, Bujard H and Reed SI: Acceleration of the G1/S phase transition by expression of cyclins D1 and E with an inducible system. Mol Cell Biol 14: 1669-1679, 1994.

36. Gartel AL and Radhakrishnan SK: Lost in transcription: p21 repression, mechanisms, and consequences. Cancer Res 65: 3980-3985, 2005. 